\title{
Penetapan Kadar Fenolik Total Ekstrak Kulit Buah Kopi Robusta (Coffea canephora L.) Di Pulau Lombok
}

\author{
Febriyanto ${ }^{a, 1^{*}}$, Nisa Isneni Hanifa ${ }^{a, 2}$, Handa Muliasari ${ }^{a, 3}$ \\ aprogram Studi Farmasi, Fakultas Kedokteran, Universitas Mataram, J1. Majapahit No. 62, Dasan Agung Baru, Mataram, 83I 26 \\ ${ }^{1}$ febrigg@gmail.com*; ${ }^{2}$ nisa.isneni.hanifa@unram.ac.id; ${ }^{3}$ handamuliasari@gmail.com \\ *korespondensi penulis
}

INFO ARTIKEL

Diterima :

25-06-202I

Direvisi :

12-07-202I

Disetujui :

I3-07-2021

\section{Kata kunci: \\ Kulit buah kopi; \\ Kopi robusta (Coffea \\ canephora L.);}

Kadar fenolik total.

\section{ABSTRAK}

Produksi kopi robusta (Coffea canephora L.) menghasilkan limbah berupa kulit buah kopi dengan proporsi sebesar 40-45\%. Kulit buah kopi dilaporkan mengandung senyawa fenolik yang berpotensi sebagai antioksidan. Kadar senyawa fenolik dapat dipengaruhi oleh faktor lingkungan. pulau Lombok memiliki perkebunan kopi yang tersebar hampir diseluruh penjuru pulau. Penelitian ini bertujuan menentukan kadar fenolik total kulit buah kopi robusta yang dikoleksi dari tiga lokasi berbeda di pulau Lombok. Sampel kulit buah kopi diekstraksi menggunakan metode sonikasi dengan pelarut etanol $70 \%$ selama 30 menit pada suhu ruang. Penentuan kadar fenolik total menggunakan metode Folin-Ciocalteu dengan standar asam galat. Kadar fenolik total dinyatakan dalam mg equivalent asam galat (GAE) per gram simplisia. Hasil analisis menunjukkan ekstrak kulit buah kopi dari lokasi desa Lamper memiliki kadar fenolik total sebesar $5.6252 \pm 0.0658 \mathrm{mg}$ GAE$/ \mathrm{g}$, kadar fenolik total ekstrak kulit buah kopi dari desa Keru sebesar 2.6626 \pm 0.0892 mg GAE/g, dan kadar fenolik total kulit buah kopi dari desa Sajang sebesar $4.6757 \pm$ $0.0528 \mathrm{mg} \mathrm{GAE} / \mathrm{g}$. Ekstrak dari ketiga lokasi berpotensi sebagai antioksidan dilihat dari kadar fenolik total yang berbeda. Berdasarkan hasil penelititan dapat diketahui bahwa kadar fenolik total ekstrak kulit buah kopi dari lokasi lamper lebih tinggi daripada lokasi Sajang dan Keru.

Key word:

Coffee pulp;

Robusta coffee (Coffea

canephora L.);

Total phenolic content.

\section{ABSTRACT}

Production of robusta coffee (Coffea canephora L.) produces coffee pulp waste with proportion of $40-45 \%$. Coffee pulp reported contain phenolic compounds that have antioxidants activity. Content of phenolic compounds can be influenced by environmental factors. Lombok Island has coffee plantations that scattered throughout the island. This study aims to determine the total phenolic content of robusta coffee pulp collected from three different locations on the island of Lombok. The coffee pulp samples extracted using the sonication method with $70 \%$ ethanol solvent for 30 minutes at room temperature. Determination of the total phenolic content of the extract using the FolinCiocalteu method with gallic acid standard. Total phenolic content is expressed in mg equivalent gallic acid (GAE) per gram of simplicia. The results of the analysis showed total phenolic content coffee pulp from Lamper village was $5.6252 \pm 0.0658 \mathrm{mg} \mathrm{GAE} / \mathrm{g}$, the total phenolic content coffee pulp from Keru village was $2.6626 \pm 0.0892 \mathrm{mg} \mathrm{GAE} / \mathrm{g}$, and the total phenolic content coffee pulp from Sajang village was $4.6757 \pm 0.0528 \mathrm{mg}$ GAE $/ \mathrm{g}$. Extract from three different location have the potential as antioxidants. Based on the results of the study, it can be seen thatcoffee pulp extract from Lamper has highest total phenolic content than coffee pulp from Sajang and Keru.

This is an open access article under the CC-BY-SA license. 


\section{Pendahuluan}

Produksi Kopi robusta di Indonesia pada tahun 2018 tercatat sebanyak 463.775 ton. provinsi Nusa Tenggara Barat menghasilkan kopi robusta sekitar 5000 ton per tahun yang sebagian besar hasil panen diproduksi di pulau Lombok (Ditjen Perkebunan, 2019). Proses pengolahan buah kopi sampai menjadi kopi bubuk menghasilkan limbah berupa kulit buah kopi. Proporsi limbah kulit buah yang dihasilkan sebanyak 40-45\% dari berat total buah kopi (Padmapriya et al., 2013).

Limbah kulit buah kopi mengandung banyak air, jika tidak diolah dengan baik dan dibuang ke drainase menyebabkan pencemaran air. Permanfaatan kulit buah kopi secara ekonomis di pulau Lombok cenderung rendah, biasanya sebagai pakan ternak dan pupuk (Juwita et al., 2017). Kulit buah kopi mulai dikembangkan secara tradisional sebagai teh dengan cara dikeringkan. Kulit buah kopi kering dilaporkan mengandung senyawa-senyawa fenolik sekitar I,8-8,56\% dari keseluruhan kandungan metabolit primer maupun sekunder. senyawa-senyawa tersebut antara lain flavan-3-ol, asam klorogenat, flavonol, antosianidin, katekin, epikatekin, rutin, tanin, dan asam ferulat(Hafsah et al., 2020).

Senyawa-senyawa fenolik memiliki berbagai aktivitas biologis salah satunya sebagai antioksidan. Senyawa fenolik meredam radikal bebas dengan cara mendonorkan satu elektron dari gugus -OH sehingga dapat menstabilkan radikal bebas (Dhurhania and Novianto, 2019). Senyawa fenolik dilaporkan menunjukkan hubungan yang sinergis antara kadar fenolik total dengan aktivitas antioksidan. Semakin tinggi kadar fenolik, maka semakin tinggi aktivitas antioksidan suatu ekstrak (Leksono et al., 2018).

Kadar senyawa fenolik dalam suatu tanaman dipengaruhi oleh beberapa faktor seperti perlakuan pasca panen, varietas tumbuhan, metode ekstraksi, pemurnian, dan faktor lingkungan. Faktor lingkungan yang berpengaruh pada kadar fenolik yaitu seperti ketinggian, $\mathrm{pH}$ tanah, suhu, kesuburan dan kelembapan tanah (Yang et al., 2018). Penelitian yang dilakukan Heeger et al (2017) menyatakan adanya perbedaan kadar fenolik pada tanaman yang tumbuh ditempat yang berbeda.

Perkebunan kopi di pulau Lombok tersebar hampir merata di seluruh kabupaten. Hal ini memungkinkan perbedaan kadar fenolik yang terdapat pada kulit buah kopi robusta (Coffea canephora L.) Penelitian yang mengkaji terkait kadar fenolik total buah kopi robusta (Coffea canephora L.) yang terdapat di pulau Lombok masih belum dilakukan. Penentuan kadar fenolik total dapat dipertimbangkan untuk pengaplikasian kulit buah kopi robusta (Coffea canephora L.) sebagai bahan baku antioksidan alami. Berdasarkan hal tersebut, maka dilakukan penelitian untuk menentukan kadar fenolik total pada sampel kulit buah kopi robusta (Coffea canephora L.) dari tiga daerah berbeda di pulau Lombok.

\section{Metode \\ Bahan}

Pelarut etanol 70\% teknis, reagen FolinCiocalteu (Merck), serbuk $\mathrm{Na}_{2} \mathrm{CO}_{3}$ (Merck), aquabides (WaterOne), dan standar asam galat (Sigma-Aldrich).

\section{Alat}

Spektrofotometer UV-Visible (Analytik Jena Specord 200 plus), sonikator (Elmasonic), vacuum rotary evaporator.

\section{Pengambilan sampel}

Sampel buah kopi robusta (Coffea canephora L.) diambil di tiga lokasi berbeda yaitu di desa Lamper, desa Keru yang berada di kabupaten Lombok Barat, dan desa Sajang yang berada di kabupaten Lombok Timur. Kriteria inklusi pengambilan sampel buah kopi yaitu matang berwarna merah dan tidak terserang hama. Setelah dipetik buah kopi dicuci dengan air mengalir dan dipisahkan kulit buah dari bagian buah yang lain.

\section{Preparasi sampel}

Sebanyak I kg kulit buah kopi robusta dijemur dibawah sinar matahari selama \pm 20 jam ditutupi dengan kain hitam (Nafisah and Widyaningsih, 2018). Setelah kering sampel dihaluskan dan diblender kemudian diayak dengan ayakan mesh 70 .

\section{Ekstraksi sampel}

Simplisia kemudian diekstrak menggunakan metode sonikasi yang dimodifikasi dari prosedur yang dillakukan oleh Kieu Tran et al (2020). Sonikasi dilakukan dengan perbandingan sampel dengan pelarut I:4 menggunakan pelarut etanol $70 \%$. Proses sonikasi dilakukan pada suhu ruang selama 30 menit. Selanjutnya hasil sonikasi difiltrasi dan diulangi proses sonikasi sebanyak dua kali. Filtrat kemudian dikumpulkan dan diuapkan menggunakan vacuum rotary 
evaporator pada suhu $40^{\circ} \mathrm{C}$ dengan kecepatan 50 rpm.

\section{Penetapan kadar fenolik total}

Pembuatan larutan induk asam galat (500 ppm) Sebanyak 0,05 gram serbuk asam galat dilarutkan dengan $100 \mathrm{~mL}$ aquabides. Kemudian dibuat variasi konsentrasi I0, 20, 30, 40, dan 50 ppm.

\section{Penentuan Operating Time (OT)}

Sebanyak $300 \mu \mathrm{L}$ larutan asam galat $30 \mathrm{ppm}$ ditambahkan dengan I,5 mL reagen FolinCiocalteu yang telah diencerkan (I:I0), larutan divortexdan didiamkan selama 8 menit.. Setelah itu ditambahkan I,2 $\mathrm{mL}$ larutan $\mathrm{Na}_{2} \mathrm{CO}_{3}$, kemudian divortex hingga homogen. Absorbansi diukur pada panjang gelombang teoritis $765 \mathrm{~nm}$ dalam rentang waktu 0-60 menit (Alfian and Susanti, 2012)

\section{Penentuan Panjang Gelombang Maksimum}

Sebanyak $300 \mu \mathrm{L}$ larutan asam galat $30 \mathrm{ppm}$ ditambahkan I,5 $\mathrm{mL}$ reagen Folin-Ciocalteu (I:I0) kemudian divortex dan didiamkan selama 8 menit. Setelah itu ditambahkan I,2 mL larutan $\mathrm{Na}_{2} \mathrm{CO}_{3}$ 7,5\% dan divortex hingga homogen. larutan diinkubasi pada suhu ruang selama operating time dan absorbansi diukur pada panjang gelombang 400-800 nm (Alfian and Susanti, 2012)

\section{Pembuatan Kurva Baku Asam galat}

Sebanyak $300 \mu \mathrm{L}$ larutan asam galat konsentrasi I0, 20, 30, 40, dan 50 ppm masingmasing ditambahkan $\mathrm{I}, 5 \mathrm{~mL}$ reagen FolinCiocalteu (I:I0), larutan divortex dan didiamkan selama 8 menit. setelah itu ditambahkan I,2 mL larutan $\mathrm{Na}_{2} \mathrm{Co}_{3}$ 7,5\% diinkubasi pada suhu ruang selama operating time absorbansi diukur pada panjang gelombang maksimum yang diperoleh dan dibuat kurva baku dengan memplorkan konsentrasi sebagai sumbu $\mathrm{x}$ dan absorbansi sebagai sumbu y (Andriani and Murtisiwi, 2018).

\section{Penentuan Kadar Fenolik Total Ekstrak Etanol Kulit Buah Kopi Robusta (Coffea canephora L.)}

Ekstrak dari ketiga lokasi masing-masing ditimbang $10 \mathrm{mg}$ dan dilarutkan ke dalam $10 \mathrm{~mL}$ aquabides. kemudian sampel diencerkan menjadi konsentrasi 200 ppm. Sebanyak $300 \mu \mathrm{L}$ larutan sampel dari ketiga lokasi ditambahkan I,5 mL reagen Folin-Ciocalteu (I:I0) kemudian divortex dan didiamkan selama 8 menit. Larutan kemudian ditambahkan I,2 $\mathrm{mL} \mathrm{Na} \mathrm{CO}_{3} 7,5 \%$.
Larutan divortex lalu diinkubasi pada suhu ruang selama operating time. Absorbansi diukur pada panjang gelombang maksimum dan dilakukan replikasi dua kali. Kadar fenolik total sampel dihitung dengan rumus (Chaithada et al., 2018):

$$
\mathrm{TPC}=\frac{\mathrm{C} . \mathrm{V} . \mathrm{fp}}{\mathrm{g}} \quad \ldots \ldots \ldots . \mathrm{I}
$$

Keterangan :

$$
\begin{array}{ll}
\text { TPC } & =\text { Total Phenolic Content } \\
\mathrm{C} & =\text { konsentrasi fenolik }(\mathrm{x}) \\
\mathrm{V} & =\text { volume ekstrak }(\mathrm{mL}) \\
\mathrm{fp} & =\text { faktor pengenceran } \\
\mathrm{g} & =\text { berat sampel (gram) }
\end{array}
$$

\section{Hasil dan Pembahasan}

\section{Pembuatan ekstrak}

Sebanyak $2 \mathrm{~kg}$ sampel buah kopi robusta diambil dari masing-masing tempat. Buah yang berwarna merah dipilih karena memiliki kandungan metabolit sekunder lebih tinggi dibandingkan saat masih berwarna hijau (Hu et al., 2020). Ketinggian lokasi pengambilan sampel di desa Lamper, desa Keru, dan desa Sajang berturut-turut adalah 40 mdpl, 223 mdpl, dan 863 mdpl.

Sampel kulit buah kopi robusta dijemur dibawah sinar matahari agar metabolit sekunder tidak rusak akibat pemanasan berlebih (Puspaningrum and Sumadewi, 2019). Simplisia kulit buah kopi dihaluskan dan diayak menggunakan mesh 70 yang bertujuan meningkatkan luas permukaan partikel saat kontak dengan pelarut saat dilakukan ekstraksi (Ardyanti, Suhendra and Ganda Puta, 2020).

Simplisia kulit buah kopi robusta kemudian diekstraksi dengan pelarut etanol $70 \%$ dan menggunakan metode sonikasi. Filtrat dipekatkan bantuan vaccum rotary evaporator dengan suhu $40^{\circ} \mathrm{C}$ untuk mencegah rusaknya senyawa fenolik yang bersifat termolabil (Pandey and Tripathi, 2014).

Data hasil rendemen ekstrak dapat dilihat pada tabel I. Hasil rendemen ekstrak tertinggi diperoleh dari sampel desa Sajang kemudian diikuti oleh sampel desa Lamper dan desa Keru. Hasil rendemen ini menggambarkan banyaknya senyawa aktif yang tersari. Sebagaimana yang dikemukakan Hasnaeni et al (2019) bahwa semakin tinggi senyawa aktif pada suatu sampel ditunjukkan dengan jumlah rendemen yang dihasilkan. Hasil rendemen ekstrak pada masingmasing sampel dalam penelitian ini tergolong tinggi karena ekstraksi senyawa fenolik yang bersifat semi polar lebih baik dilakukan dengan pelarut etanol dengan konsentrasi antara 50-70\% 
dibandingkan dengan air yang bersifat polar dan pelarut non polar (Suhendra et al., 2019). Sonikasi dipilih sebagai teknik ekstraksi karena waktu ekstraksi menjadi efisien karena radiasi ultrasonik menyebabkan fenomena kavitasi untuk meningkatkan permeabilitas dari dinding sel, meningkatkan kelarutan dan transfer zat yang tersari dalam waktu yang singkat (Sholihah et al., 2017). Sonikasi dilaporkan meningkatkan rendemen hasil ekstraksi pada senyawa polifenol sebesar 6\%-35\% dibanding metode konvensional seperti maserasi(Garcia-Salas et al., 2010).

Tabel I. Rendemen Ektrak

\begin{tabular}{cccc}
\hline $\begin{array}{c}\text { Asal } \\
\text { sampel } \\
\text { kopi }\end{array}$ & $\begin{array}{c}\text { Berat } \\
\text { serbuk } \\
\text { simplisia } \\
\text { (g) }\end{array}$ & $\begin{array}{c}\text { Berat } \\
\text { ekstrak } \\
\text { kental (g) }\end{array}$ & $\begin{array}{c}\text { Rendemen } \\
\text { ekstrak(\%) }\end{array}$ \\
\hline Lamper & I00 & 15,709 & 15,709 \\
Keru & 100 & 14,002 & 14,002 \\
Sajang & 100 & 29,042 & 23,042 \\
\hline
\end{tabular}

\section{Penetapan kadar fenolik total}

Penetapan kadar fenolik total menggunakan metode Folin-Ciocalteu dengan bantuan instrumen spektrofotometer UV-Vis. Prinsip deteksi senyawa fenolik dengan metode FolinCiocalteu adalah adanya reduksi senyawa fosfotungstat-fosfomolibdat oleh senyawa fenolik dan membentuk kompleks molibdenum tungsten yang berwarna biru. Semakin pekat warna biru yang dihasilkan menandakan semakin banyaknya kandungan senyawa fenol yang terdeteksi. Reaksi antara senyawa fenolik dengan Folin-Ciocalteu terjadi pada suasana basa agar membentuk ion fenolat dari senyawa fenolik. Oleh karena itu untuk membentuk suasana basa ditambahkan $\mathrm{Na}_{2} \mathrm{CO}_{3}$ (Senet et al., 2018).

Pengukuran kurva baku menggunakan standar asam galat karena merupakan fenol sederhana, murah dan stabil. Kurva baku asam galat dibuat variasi konsentrasi I0, 20, 30, 40, dan 50 ppm. Pengukuran absorbansi kurva baku asam galat dilakukan pada panjang gelombang $752 \mathrm{~nm}$ dengan operating time selama 40 menit. Absorbansi dan kurva baku standar asam galat dapat dilihat pada tabel 2 dan gambar I.

Persamaan regresi yang diperoleh dari pengukuran kurva baku yaitu y $=0.103 x+$ 0.147 dengan nilai $\mathrm{R}^{2}=0,989$. Hasil kadar fenolik total ekstrak kulit buah kopi dari ketiga lokasi dapat dilihat pada tabel 3.
Tabel 2.Data Absorbansi Asam Galat

\begin{tabular}{cc}
\hline Konsentrasi (ppm) & Absorbansi \\
\hline I0 & 0,2355 \\
\hline 20 & $0,359 \mathrm{I}$ \\
\hline 30 & 0,4828 \\
\hline 40 & 0,5464 \\
\hline 50 & 0,6569 \\
\hline
\end{tabular}

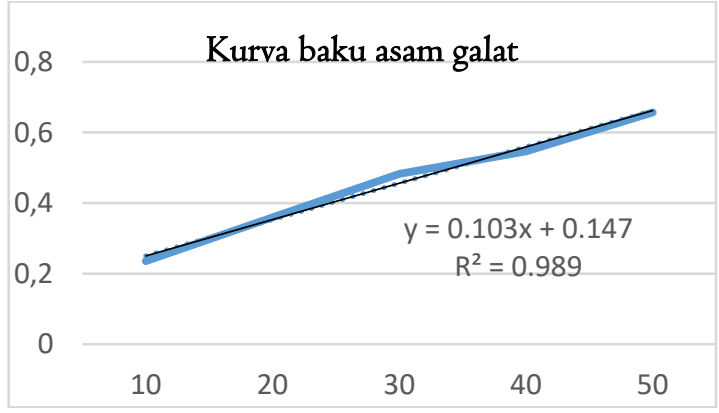

Gambar I. Kurva baku asam galat

Berdasarkan hasil yang diperoleh, dapat dilihat kadar fenolik total masing-masing sampel menunjukkan adanya perbedaan. Sampel kulit buah kopi dari lokasi lamper memiliki kadar fenolik tertinggi dibanding sampel kulit buah kopi dari lokasi keru dan sajang yaitu sebesar 5,6262 $\pm 0.0658 \mathrm{mg} \mathrm{GAE} / \mathrm{g}$. Sedangkan kadar fenolik total sampel kulit buah kopi dari lokasi keru dan sajang berturut-turut sebanyak 2.6626 $\pm 0.0892 \mathrm{mg} \mathrm{GAE} / \mathrm{g}$ dan $4.6757 \pm 0.0528 \mathrm{mg}$ GAE/g. Perbedaan kadar fenolik pada sampel kulit buah robusta dapat disebabkan oleh beberapa faktor seperti faktor genetik, lingkungan tempat tumbuh, pengaruh pasca panen, dan pengaruh tanaman sekitar.

Dalam penelitian ini, faktor genetik tidak berpengaruh karena spesies kopi yang diambil sama yaitu kopi robusta. Sedangkan faktor pengaruh pasca panen juga tidak berpengaruh karena dari proses panen hingga ekstrak seluruh perlakuan terkontrol. Faktor yang dapat berpengaruh yaitu faktor kondisi lingkungan tempat tumbuh. Faktor lingkungan seperti ketinggian, suhu, kelembapan dan $\mathrm{pH}$ dapat menyebabkan perbedaan cara tanaman beradaptasi sehingga dapat mempengaruhi morfologi dan kadar metabolit primer dan sekunder pada tanaman walaupun masih dalam satu spesies yang sama (Yang et al., 2018). Ketinggian dari masing-masing tempat pengambilan sampel yang berbeda secara tidak langsung mempengaruhi kondisi lingkungan 
seperti suhu, kelembapan dan paparan sinar matahari (Liu et al., 2016). Penelitian yang mengkaji perbedaan lokasi tumbuh telah dilakukan Heeger et al (2017) pada sampel kopi yang tumbuh di Kongo, Salvador dan Honduras dan dilaporkan bahwa adanya perbedaan serupa pada metabolit sekunder akibat pengaruh dari perbedaan lokasi tumbuh.

Hasil penentuan kadar fenolik total yang terdapat dalam ekstrak kulit buah kopi menandakan bahwa kulit buah kopi berpotensi sebagai antioksidan. Penelitian (Aryal et al., 2019) melaporkan bahwa terdapat hubungan yang linier terhadap kadar fenolik total dengan aktivitas antioksidan. Pernyataan tersebut didukung oleh (Wirasti, 2019) yang menyatakan semakin tinggi kadar fenolik pada suatu sampel tanaman maka semakin tinggi aktivitas antioksidan yang dihasilkan.

Tabel 3.Hasil Penetapan Kadar Fenolik Total Ekstrak Kulit Buah Kopi Dari Tiga Lokasi Berbeda

\begin{tabular}{|c|c|c|c|c|c|}
\hline Sampel & Replikasi & $\begin{array}{c}\text { Konsentrasi } \\
\text { (ppm) }\end{array}$ & Absorbansi & $\begin{array}{l}\text { Kadar Fenolik } \\
\text { Total (mg } \\
\text { GAE/g) }\end{array}$ & $\begin{array}{l}\text { Rerata Kadar } \\
\text { Fenolik Total } \\
\text { (mg GAE/g) }\end{array}$ \\
\hline \multirow[t]{2}{*}{ Lamper } & I & \multirow[b]{2}{*}{200} & 0,5380 & 5,6942 & \multirow[b]{2}{*}{$\begin{array}{c}5,6252 \pm \\
0.0658\end{array}$} \\
\hline & $\begin{array}{l}2 \\
3\end{array}$ & & $\begin{array}{l}0,5290 \\
0,5328\end{array}$ & $\begin{array}{l}5,5631 \\
5,6184\end{array}$ & \\
\hline \multirow[t]{2}{*}{ Keru } & $\begin{array}{l}\mathrm{I} \\
2\end{array}$ & \multirow[t]{2}{*}{200} & $\begin{array}{l}0,3327 \\
0,3228\end{array}$ & $\begin{array}{l}2,7044 \\
2,5602\end{array}$ & \multirow[t]{2}{*}{$\begin{array}{c}2,6626 \pm \\
0.0892\end{array}$} \\
\hline & 3 & & 0,3340 & 2,7233 & \\
\hline \multirow[t]{2}{*}{ Sajang } & $\mathrm{I}$ & & 0,4698 & 4,7010 & \multirow[b]{2}{*}{$\begin{array}{c}4,6757 \pm \\
0.0528\end{array}$} \\
\hline & $\begin{array}{l}2 \\
3\end{array}$ & 200 & $\begin{array}{l}0,4705 \\
0,4639\end{array}$ & $\begin{array}{l}4,7 \mathrm{II} 2 \\
4,6150\end{array}$ & \\
\hline
\end{tabular}

\section{Simpulan dan Saran}

Kadar fenolik total ekstrak etanol kulit buah kopi robusta (Coffea canephora L.) yang dikoleksi dari desa Lamper, desa Keru, dan desa Sajang berturut-turut yaitu sebesar $5.6252 \pm$ $0.0658 \mathrm{mg}$ GAE $/ \mathrm{g}, 2,6626 \pm 0.0892 \mathrm{mg}$ $\mathrm{GAE} / \mathrm{g}$, dan $4.6757 \pm 0.0528 \mathrm{mg} \mathrm{GAE} / \mathrm{g}$. Dari tiga lokasi pengambilan sampel menunjukkan adanya perbedaan kadar fenolik dan berpotensi sebagai antioksidan. Sampel dari desa Lamper memiliki kadar fenolik tertinggi dibandingkan sampel dari desa keru dan sajang.

\section{Daftar Pustaka}

Alfian, R., dan Susanti, H. (2012). Penetapan kadar fenolik total ekstrak metanol kelopak bunga rosella merah (Hibiscus sabdariffa Linn) dengan variasi tempat tumbuh secara spektroforonmetri. Pharmaciana, 2(I), 73-80

Andriani, D., dan Murtisiwi, L. (2018). Penetapan kadar fenolik total ekstrak etanol bunga telang (Clitoria ternatea L.) dengan spektrofotometri $\mathrm{UV}_{\mathrm{v}} \mathrm{V}$ is. Cendekia Journal of Pharmacy, 2(I), 32-38

Ardyanti, N. K. N. T., Suhendra, L., Ganda Puta, G. P. (2020). Pengaruh ukuran partikel dan lama maserasi terhadap karakteristik ekstrak virgin coconut oil wortel (Daucus carota L.) sebagai pewarna alami. Jurnal Rekayasa Dan Manajemen Agroindustri, 8(3), 423-434

Aryal, S., Baniya, M. K., Danekhu, K., Kunwar, P., Gurung, R., dan Koirala, N. (2019). Total phenolic content, flavonoid content and antioxidant potential of wild vegetables from western Nepal. Plants, 8(4), I-I2

Chaithada, P., Supapan, J., Rodthuk, P., danChainarong, S. (2018). Total flavonoids, total phenolic content and antioxidant activity from fruits, leaves, twigs and flowers of Mesua ferrea L. 
Walailak Journal of Science and Technology, I5(4), 295-304

Dhurhania, C. E., dan Novianto, A. (2019). Uji kandungan fenolik total dan pengaruhnya terhadap aktivitas antioksidan dari berbagai bentuk sediaan sarang semut (Myrmecodia pendens). Jurnal Farmasi Dan IImu Kefarmasian Indonesia, 5(2), 62-68

Ditjen Perkebunan. (2019). Statistik Perkebunan Kopi Indonesia. Kementerian Pertanian : Jakarta.

Garcia-Salas, P., Aranzazu, M.S., Antonio, S.C., dan Alberto, F.G., (2010). Phenoliccompound-extraction system for fruit and vegetable samples. Molecules, I5(I2), 88I3-8826

Hafsah, H., Iriawati, I., dan Syamsudin, T. S. (2020). Dataset of volatile compounds from flowers and secondary metabolites from the skin pulp, green beans, and peaberry green beans of robusta coffee. Data in Brief, 29, I-9

Hasnaeni., Wisdawati., dan Usman, S. (2019). Pengaruh metode ekstraksi terhadap rendemen dan kadar fenolik ekstrak tanaman kayu beta-beta (Lunasia amara Blanco). Jurnal Farmasi Galenika (Galenika Journal of Pharmacy), 5(2), I75-I82

Heeger, A., Kosiska-Cagnazzo, A., Cantergiani, E., dan Andlauer, W. (2016). Bioactives of coffee cherry pulp and its utilisation for production of Cascara beverage. Food Chemistry, 221, 969-975

Hu, G., Peng, X., Wang, X., Li, X., Li, X., dan Qiu, M. (2020). Excavation of coffee maturity markers and further research on their changes in coffee cherries of different maturity. Food Research International, I32, I-7

Juwita, A. I., Mustafa, A., dan Tamrin, R. (2017). Studi pemanfaatan kulit kopi arabika (Coffee arabica L.) sebagai mikroorganisme lokal (MOL). Agrointek, II(I), I-7

Kieu Tran, T. M., Kirkman, T., Nguyen, M., dan Van Vuong, Q. (2020). Effects of drying on physical properties, phenolic compounds and antioxidant capacity of Robusta wet coffee pulp (Coffea canephora). Heliyon, 6(7), I-7

Leksono, W. B., Pramesti, R., Santosa, G. W., dan Setyati, W. A. (2018). Jenis pelarut metanol dan N-Heksana terhadap aktivitas antioksidan ekstrak rumput laut gelidium sp. dari pantai drini Gunungkidul - Yogyakarta. Jurnal Kelautan Tropis, 2I(I), 9-I6

Liu, W., Yin, D., Li, Na., Hou, X., Wang, D., Li, D., dan Liu, J. (2016). Influence of environmental factors on the active substance production and antioxidant activity in Potentilla fruticosa L. and its quality assessment. Scientific Reports, 6(2015), I-I8

Nafisah, D., dan Widyaningsih, T. D. (2018). Kajian metode pengeringan dan rasio penyeduhan pada proses pembuatan teh cascara kopi arabika (Coffea arabika L.). Jurnal Pangan Dan Agroindustri, 6(3), 37-47

Pandey, A., dan Tripathi, S. (2014). Concept of standardization, extraction and pre phytochemical screening strategies for herbal drug. Journal of Pharmacognosy and Phytochemistry, 2(5), I I5-I I9

Padmapriya, R., Tharian, J. A., dan Thirunalasundari, T. (2013). Coffee waste management-An overview. Int $J$ Curr Sci, 9 (February), 83-9I

Puspaningrum, dan Sumadewi, D, (2019). Pengaruh metode pengeringan terhadap kandungan total fenol cascara kopi arabika (Coffea arabica L.), Prosiding, Siniesa, 423-428

Senet, M. R. M., Raharja, I. G. M. A. P., Darma, I. K. T., Prastakarini, K. T., Dewi, N. M. A., dan Parwata, I. M. O. A. (2018). Penentuan kandungan total flavonoid dan total fenol dari akar kersen (Mutingia calabura) serta aktivitasnya sebagai antioksidan. Jurnal Kimia, I2(I), I3-I8

Sholihah, M., Ahmad, U., dan Budiastra, I. W. (2017). Aplikasi gelombang ultrasonik untuk meningkatkan rendemen ekstraksi dan efektivitas antioksi dan kulit manggis. JTEP Jurnal Keteknikan Pertanian, 5(2), I6I-I68

Suhendra, C. P., Widarta, I.W.R., dan Wiadnyani, A.A.I.S. (2019). Pengaruh konsentrasi etanol terhadap aktivitas antioksidan ekstrak rimpang ilalang (Imperata cylindrica (L) Beauv.) pada ekstraksi menggunakan gelombang ultrasonik. Jurnal Ilmu dan Teknologi Pangan, 8(I), 27-35

Wirasti. (2019). Penetapan kadar fenolik total, flavonoid total, dan uji aktivitas 
antioksidan ekstrak daun benalu petai (scurrula atropurpurea dans.) beserta penapisan fitokimia. Journal of Pharmaceutical and Medicinal Sciences, $4(\mathrm{I}), \mathrm{I}-5$

Yang, L., Wen, K. S., Ruan, X., Zhao, Y. X., Wei, F., dan Wang, Q. (2018). Response of plant secondary metabolites to environmental factors. Molecules, 23(4), I-26 